\title{
Octabor (Disodium Octaborate Tetrahydrate) As a Low Toxicity Control Tactic for the Spotted Wing Drosophila, Drosophila Suzukii (Matsumura)
}

\author{
Troy Cloutier
}

School of Biology and Ecology

311 Deering Hall, University of Maine, Orono, Maine, United States

Tel: 1-207-581-2987 E-mail: troy.cloutier1@ maine.edu

\author{
Francis Drummond (Corresponding author) \\ School of Biology and Ecology \\ University of Maine Cooperative Extension
}

305 Deering Hall, University of Maine, Orono, Maine, United States

Tel: 1-207-581-2989 E-mail: fdrummond@maine.edu

\author{
Judith Collins
}

School of Biology and Ecology

307 Deering Hall, University of Maine, Orono, Maine, United States

Tel: 1-207-581-2868 E-mail: collinsj@ maine.edu

Received: June 1, 2018

doi:10.5296/jas.v6i3.13232
Accepted: June 19, 2018

URL: https://doi.org/10.5296/jas.v6i3.13232 


\section{Abstract}

The recently introduced spotted wing drosophila is one of the most serious pests in small fruit production in the United States and Europe. Most control relies upon multiple applications of synthetic insecticides. In an effort to find less-toxic insecticides to consumers, farm workers, and wildlife, we conducted two laboratory trials and a semi-field trial in order to assess the potential for disodium octaborate tetrahydrate formulated and sold as Octabor ${ }^{\circledR}$ (U.S. Borax, Inc.) as a control for spotted wing drosophila in wild blueberry. We found that Octabor at 0.6 and $1.0 \%(\mathrm{w} / \mathrm{v})$ applied to wild blueberry fruit resulted in higher mortality of flies than non-treated control fruit. Addition of sugar to Octabor enhanced mortality in one of the two trials, with an interaction between sugar addition and Octabor rate suggesting that the addition of sugar provided the greatest enhancement at the low rate. Our semi-field study showed that an apparent repellency effect of Octabor provided protection of fruit from infestation for up to 3 days. Also in the semi-field study, we observed a delayed effect on fly mortality. Increased fly mortality occurred over time, relative to the non-treated control fruit. The greatest fly mortality, relative to the non-treated control, resulted from flies being exposed to fruit treated 3 and 7 days prior to fly exposure, but not immediately after the treatment of Octabor. We speculate on why this type of delay in mortality might have occurred.

Keywords: Spotted wing drosophila, Octabor, Wild blueberry, Repellency, Mortality

\section{Introduction}

Since its introduction to the Continental United States from Asia in 2008, the spotted wing drosophila, Drosophila suzukii (Matsumura), has been a concern among growers of soft fruits (Ballman et al., 2017). The spotted wing drosophila is a wide spread pest due to its serrated ovipositor and polyphagous nature. Drosophila melanogaster Meigen lay their eggs in rotting fruits while the spotted wing drosophila lay eggs in ripe soft-skinned fruits (Asplen et al., 2015). Current spotted wing drosophila management is mostly based upon use of synthetic insecticide applications, many of which are organophosphates and toxic to farm workers (Clavert et al., 2008). Although, cultural control tactics and biological control such as mass trapping, exclusion netting, sanitation during and after harvest, conservation of predators, use of pathogens, and removal of wild fruit hosts are being researched (Bohinc and Trdan, 2014; Alnajjar et al., 2017; Alnajjar et al., 2018; Ballman et al., 2017; Ballman and Drummond, 2018). An insecticide for spotted wing drosophila control with low mammalian toxicity would help minimize health risks to farm workers, consumers, and exposed wildlife.

Boric acid powder has been commonly used as a less toxicity alternative to other synthetic insecticides when controlling household pests such as cockroaches. Symptoms of boric acid poisoning in cockroaches indicate that boric acid has a neurotoxic effect on insects as well as causing starvation by altering the insect's midgut epithelial cells by increasing their thickness leading to disruption of nutrient absorption (Habes et al., 2006; Dayer and Karvandian, 2016). The concentration of boric acid used against insects has little effect on human health. Many household products including skin powder, ointments, and mouthwash contain boric acid (Anonymous, 2017). Erdem et al. (2016) show that sodium borates can have a negative effect 
on Drosophila as well. In a laboratory study with the common vinegar fly, Drosophila melanogaster Meigen, they showed that increased mortality and decreased fecundity occurred when fed diets containing borax (sodium tetraborate).

The objective of our research was to test the efficacy of disodium octaborate tetrahydrate (formulated as the commercial product Octabor ${ }^{\circledR}$ ) for control against the spotted wing drosophila. Two laboratory trials and a semi-field bioassay were conducted to test the potential of boron as a control product.

\section{Materials and Methods}

\subsection{Drosophila suzukii colony source, rearing procedures, and crop plants}

Adult D. suzukii were collected in wild blueberry ( $V$. angustifolium Aiton) plants in Stillwater, Maine, USA in July 2016. Flies were reared on Instant Drosophila Medium formula 4-24 (Carolina Biological Supply Co., Burlington, NC) and held in $7.3 \times 2.0 \mathrm{~cm}$ Drosophila culture tubes in the laboratory at $20-23^{\circ}$ C. Newly emerged adult D. suzukii were transferred to new media every 2 to $3 \mathrm{wk}$. The culture was periodically inspected for contamination by other Drosophila species, and if other species were found we started new colonies using adult D. suzukii from our original stock colony in new culture tubes. All wild blueberry crop plants (Vaccinium angustifolium Aiton) used in both the laboratory and semi-field experiments were wild genotypes of unknown genetic identity. Wild blueberry has no cultivars as it is a wild crop plant that is commercially managed.

\subsection{Laboratory control of spotted wing drosophila with Octabor. 2016/2017}

Octabor $^{\circledR}$ (disodium octaborate tetrahydrate, U.S. Borax Inc.) was evaluated in the laboratory to assess its potential to control spotted wing drosophila adults. Two trials were conducted. In the first trial, two rates of Octabor were tested, $0.6 \% \mathrm{v} / \mathrm{w}(1.2 \mathrm{~g}$ in $200 \mathrm{ml}$ water $)$ and $1.0 \% \mathrm{v} / \mathrm{w}$ $(2.0 \mathrm{~g}$ in $200 \mathrm{ml}$ water) with and without the addition of $16 \mathrm{oz} / \mathrm{acre}$ of sugar $(0.957 \mathrm{~g})$ as a feeding stimulant. In the second trial, a single rate was tested $(0.6 \% \mathrm{v} / \mathrm{w}(1.2 \mathrm{~g}$ in $200 \mathrm{ml}$ water $)$ with and without $16 \mathrm{oz} / \mathrm{acre}(0.957 \mathrm{~g})$ of sugar. Groups of 6-10 laboratory-reared flies were placed in sterilized ( $1: 10$ bleach solution) plastic cages $(9 \times 4.38 \times 4.13$ in $)$ with five raspberries. All fruit was washed with tap water and allowed to air dry before each trial. Prior to introduction of the flies into the cages, the fruit was treated by mixing the various rates in a lab bench mister set to the finest droplet size. The sprayer was a LaMi Fine Mist Sprayer (LaMi Products, Huntingdon Valley, PA, USA) with a spray pressure of about $70 \mathrm{kPa}$ (10 psi) resulting in approximately $0.5 \mu \mathrm{l}$ applied per treatment dish. Two sprays (enough to wet the surface) were applied to the fruit that was spread out in a single layer in an open Petri dish $(100 \times 15 \mathrm{~mm})$. For the first trial there were four replications of each treatment and four non-treated controls. Non-treated controls were treated with water only. For the second trial there were five replications of each treatment and five non-treated controls. Each trial used different cohorts of flies, but within a trial all replicates were set up with flies from the same cohort. Flies were introduced into the cages after the material had dried on the fruit (1hr post application). Cages were kept on a laboratory bench at room temperature $\left(20-22{ }^{\circ} \mathrm{C}\right)$ and monitored daily for one week and the numbers of dead and live flies were recorded. In the 
second trial, the number of flies on the fruit was also recorded at each sampling interval.

2.3 Control of spotted wing drosophila with Octabor, a semi-field bioassay. 2017.

Octabor was evaluated in a semi-field bioassay to assess its potential to control spotted wing drosophila. Because our laboratory findings suggested that addition of sugar only enhanced Octabor at the low dose and only in one trial, we decided not to add sugar to the application of Octabor in the field since sugar can result in attraction of non-target beneficial insects and in sooty mold growth on leaves and fruit (Hagen and Hale, 1974; Summy and Little, 2008). Octabor $(1.0 \% \mathrm{w} / \mathrm{v})$ was applied to a crop-year blueberry field at Jonesboro, ME on 31 July. The material was applied in 25 gallons of water-mixture per acre with a $\mathrm{CO}_{2}$-propelled, 80-inch boom sprayer (76-inch swath) equipped with four, flat-spray 8002 VS TeeJet ${ }^{\circledR}$ nozzles operating at $35 \mathrm{psi}$ and at a slow walking speed. Speed was regulated using a metronome. At 0 (material allowed to dry on foliage for 4 hours), 3, and 7 days after treatment (DAT), stems containing leaves and ripe berries were cut off the bushes and placed in water picks $(10 \mathrm{~cm}$ long single anchor water pick, AquaPic ${ }^{\circledR}$ brand) inside $32 \mathrm{oz}$ clear plastic deli cups. The water picks were inserted through a hole in the bottom of the container such that the lip of the water pick was even with the bottom of the cup. Berries ( $n=6$ to 10) were removed from the stems and placed in wire mesh containment boats to reduce loss of residues on the berries. Ten adult SWD ( 5 male, 5 female) that were between 2 and 5 days old were removed from a laboratory colony, anesthetized with $\mathrm{CO}_{2}$, and added to the cups. There were four replicates + four non-treated controls for each DAT sample. To limit fly mortality, cotton balls moistened with water were placed in each cup, and a 1oz portion cup was filled with drosophila diet (Instant drosophila medium, Carolina Biological Supply Company, Burlington, North Carolina) was placed in each cup to provide food for the flies. To minimize moisture build up, lids had a $5 \mathrm{~cm}$ diameter hole cut in them and fine mesh affixed over the hole using hot glue. Cups with collected blueberry fruit and flies were placed in an environmental chamber at $25^{\circ} \mathrm{C}, 75 \% \mathrm{RH}$, and a 16:8 L:D cycle. Adult mortality was assessed daily for 8 to 10 days; fruit infestation was assessed after one week using the Salt Extraction Method described in Drummond et al. (2017).

\subsection{Statistical methods.}

In the laboratory experiment logistic regression was used to test for treatment effects (JMP, 2015). The analyses were performed by trial. In the semi-field experiment logistic regression was used compare adult mortality and fruit infestation between Octabor-treated and non-treated controls and Generalized Estimating Equations were used to conduct a repeated measures logistic regression (Hardin and Hilbe, 2003). 


\section{Results}

From the two laboratory experiments we found that exposure to boron formulated as Octabor, increased fly mortality over the non-treated control by day 6 post application $\left(\mathrm{X}_{(1)}^{2}=51.252\right.$, $\mathrm{P}<0.0001$, Fig. $1 \mathrm{~A} ; \mathrm{X}_{(1)}^{2}=3.103, \mathrm{P}=0.078$, trial 1 and trial 2 respectively, Fig. 1B;). Fly mortality in the non-treated controls was low in both trials after 6 days (11.1 and 1.8\%, respectively). However, in the second laboratory trial, a much reduced level of mortality was observed independent of sugar, comparable to that observed in the first trial with a dose of $0.6 \%(w / v)$ without the addition of sugar (Fig. 1B). Our results in trial 1 showed that while
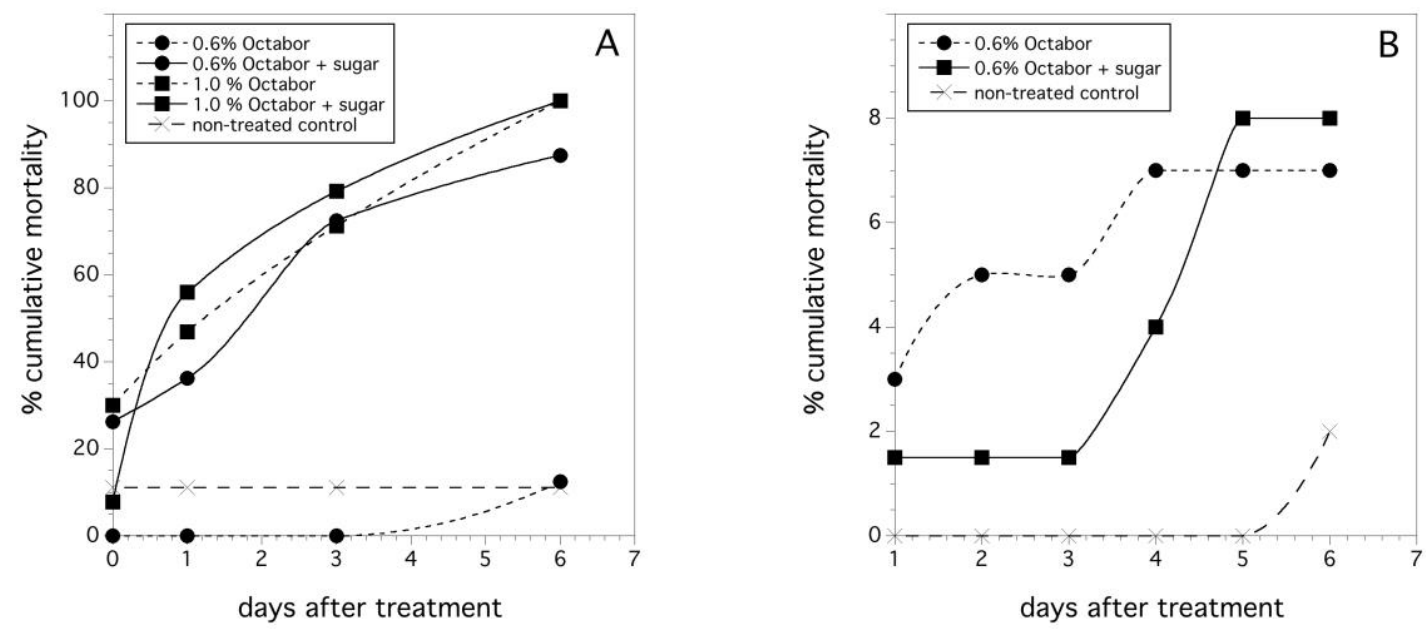

Figure 1. Percent mortality of spotted wing drosophila adults exposed to Octabor over time in Laboratory Trial 1 (A) and Trial 2 (B).

sugar may increase the effectiveness of Octabor as an insecticide, this was more obvious with the low rate of application $(0.6 \%(\mathrm{w} / \mathrm{v}))$ compared to the high rate $(1.0 \%(\mathrm{w} / \mathrm{v}))$. The interaction between sugar and Octabor rate demonstrates this for a model that includes an effect for day $\left(\mathrm{X}_{(1)}^{2}=62.852, \mathrm{P}<0.0001\right)$. We observed $87.5 \%$ mortality by day six when sugar was added to the $0.6 \%$ rate compared to only $12.5 \%$ mortality in the 0.6 rate without sugar. Fly mortality in the non-treated check was $11.1 \%$ on day six without sugar.

The semi-field bioassay showed that Octabor applied on the fruit did reduce infestation by larvae at day 0 and day 3 after application (Fig. 2); though, all fruits were infested by day 7 . This interaction between time (days) and treatment was significant $\left(\mathrm{X}^{2}{ }_{(4)}=16.771, \mathrm{P}=0.012\right)$. This effect was not strong, as there was high variation among replicates; therefore, the difference between the Octabor-treated fruit and the non-treated fruit at each date was significant only at $\mathrm{P}=0.10\left(\mathrm{X}_{(1)}^{2}=2.721\right)$. However, when evaluating fruit infestation over all the dates, there was a strong effect on infestation when comparing Octabor-treated fruit to non-treated fruit $\left(\mathrm{X}_{(1)}^{2}=15.623, \mathrm{P}<0.0001\right)$. When we looked at mortality for flies confined to arenas either with Octabor-treated fruit or control (non-treated) fruit, we found a 


\section{Macrothink}

significant Octabor effect (Fig. 3). However, the pattern of mortality was not as expected. We observed no difference in mortality when flies were confined to fruit that had just been treated with Octabor compared to fruit of the non-treated control. We did find significantly higher mortality in the Octabor treatment relative to the control for day 3 and day 7 fruit.

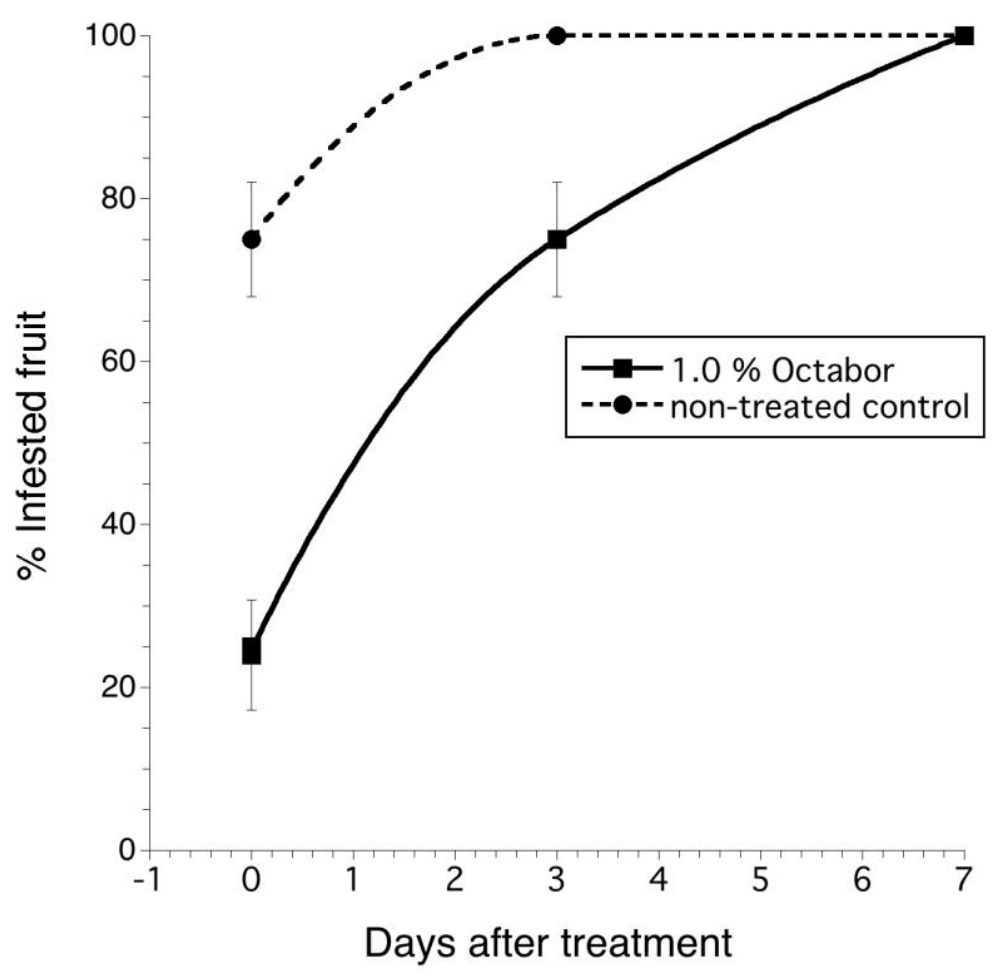

Figure 2. Percent of fruit infested with spotted wing drosophila larvae in the semi-field trial $(n=4$ replicates of 10 flies per replicate), error bars are normal approximations of binomial standard errors. 


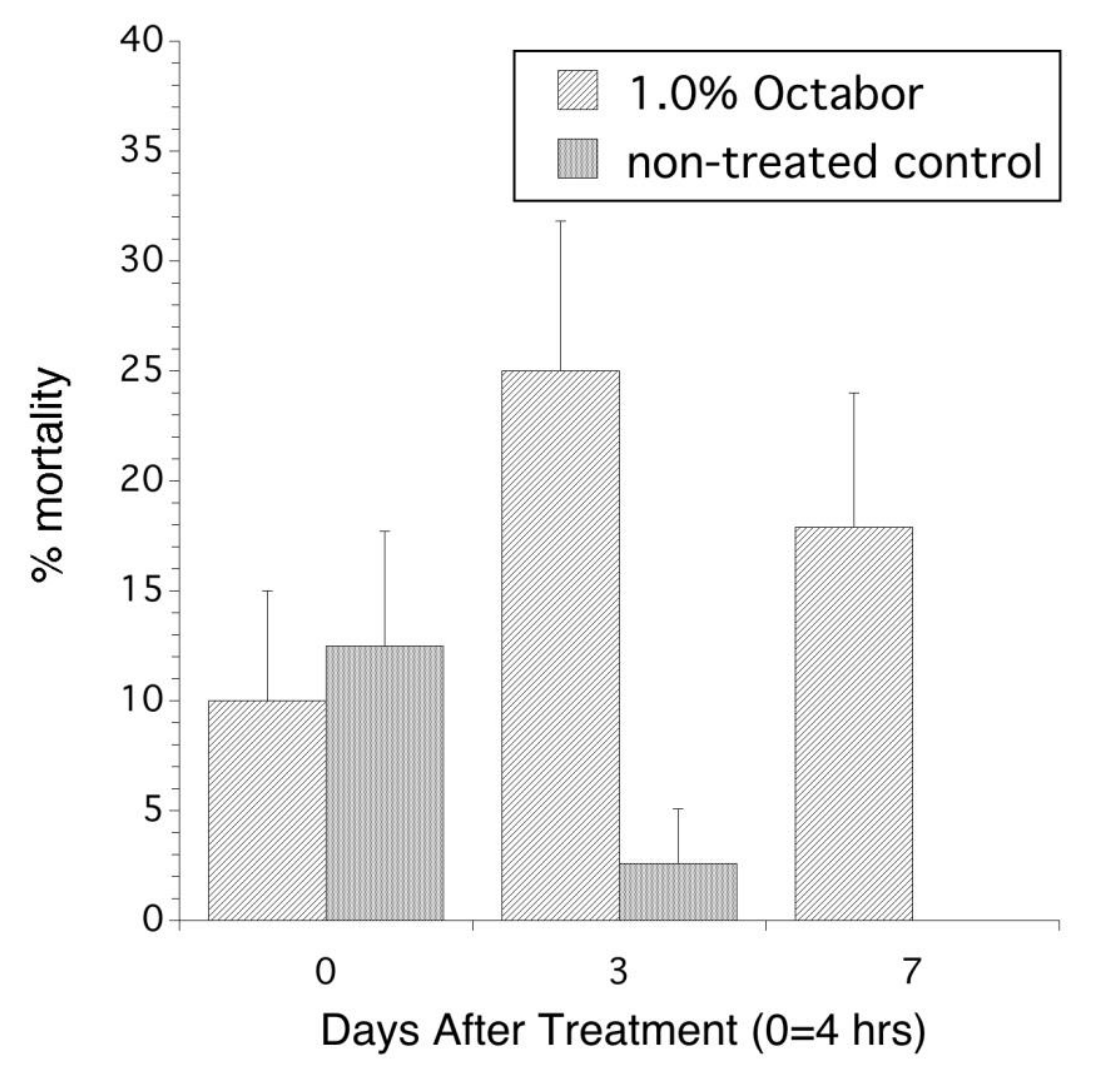

Figure 3. Percent mortality of spotted wing drosophila adults over time in the semi-field trial $(n=4$ replicates of 10 flies per replicate), error bars are normal approximations of binomial standard errors..

\section{Discussion}

Few insecticides with low mammalian toxicity have shown enough promise for control of the spotted wing drosophila that they are recommended for wild blueberries (Yarborough et al. 2018). Insecticides formulated with spinosyns are one such group of insecticides. Neonicotinoid insecticides and neem are recommended, but only for the initial applications during the beginning of spotted wing drosophila fruit attack since they are not highly effective in protecting fruit from infestation under high fly pressure. However, insecticides with low mammalian toxicity may have a role in spotted wing drosophila pest management when they are incorporated with other tactics such as early harvest, mass trapping, or exclusion netting (Alnajjar et al. 2017; Cormier et al., 2015; Hampton et al., 2014).

Our research with Octabor showed that even in the laboratory this insecticide might be inconsistent in effect. The first trial suggests that imbibing Octabor through the addition of a 
sugar feeding stimulant enhances fly mortality and that this was most noticeable at the lower dose. The phagostimulant effect of sugar added to baits and insecticides has been well documented with the spotted wing drosophila (Loeb et al., 2013; Hamby and Becher, 2016; Knight et al., 2016; and Rice et al., 2017; Fanning et al., 2018). Sugar enhances attraction of flies to insecticide deposits on plant tissue and increases efficacy of stomach poisons by increasing consumption of insecticide laden sugar droplets. Sugar as a bait increases trap efficacy as its fermentation attracts spotted wing drosophila adults as well. In fact these studies have shown that not only sugar acts as a phagostimulant to these flies, but corn gluten and yeast are also phagostimulants. However, trial 2 showed no effect of a sugar feeding stimulant. Both the sugar and no sugar addition Octabor treatments resulted in similar fly mortality as the non-sugar low dose Octabor treatment observed in trial 1. Therefore, it may have been the case that in trial 2 flies did not feed on the sugar either due to the physiological state of hunger in the flies or due to habituation of flies to the sugar which has been documented by Çevik and Erden (2012). This aspect of enhancement of Octabor through addition of a sugar feeding stimulant may present obstacles in the use of this insecticide in the field where competition for carbohydrates in a natural heterogeneous environment might reduce feeding by flies of Octabor on fruit. This has been documented for ants with insecticide baits (Sudd and Sudd, 1985). In addition, sugar concentration on wild blueberry fruits has been shown to increase the natural microbial community on the fruit (Wu et al., 2017). This could result in the metabolism of the fruit borne sugars, thereby, reducing the attraction and phagostimulation behavior in spotted wing drosophila on fruit. The dose of sodium borates in the form of boric acid delivered in sugar baits has been intensively studied in ants. A range of doses can result in the behavioral response in ants attracted to baits as being either phagostimulatory or repellent. Klotz et al., (2000) demonstrated that doses less than $1 \%$ boric acid in sugar baits were phagostimulatory, whereas, doses greater than $1 \%$ were repellent to Argentine ants (Linepithema humile (Mayr)). However, this behavioral response to dose appears to be species-specific. The carpenter ant exhibits phagostimulation at doses up to $2 \%$ boric acid in sugar baits (Klotz and Moss, 1996) and the imported fire ant (Solenopsis invicta Buran) exhibits phagostimulation at doses up to 5\% boric acid (Klotz et al., 1997).

The combined results of the laboratory studies and the semi-field bioassay show future potential for Octabor or other formulations of sodium borate as a least-toxic insecticide control for the spotted wing drosophila. However, more research is required before applying boron in an agricultural context such as practiced in the residential environment (Horton et al., 2011). Our semi-field bioassay showed that high concentrations of Octabor can protect fruit from infestation for short periods of time. Fruit in the field that was treated with Octabor received less larval infestation for up to seven days (Fig. 2). While Figure 3 suggests that a field application does not kill flies immediately, it apparently prevents them from laying eggs in fruit. However, the potency of sodium borates and boric acid esters is short lived under certain pH environments (Van Duin et al., 1984) and would need to be extended before serving as a useful repellent. Although, this might not have to be greatly enhanced since some current insecticides used against spotted wing drosophila such as Entrust ${ }^{\circledR}$ (spinosyns) only have an effective activity of 1 day and malathion (several formulations) only has an effective 
activity of 3 days (Collins and Drummond, 2014; 2016). We do not know whether the "apparent" repellency effect to Octabor is indeed due to repellency of adult ovipositing females such that they do not land on the fruit or lay fewer eggs in treated fruit, or if Octabor causes mortality of oviposited eggs and larvae inside the fruit; although, in the early stages of our experiment (day 0 to day 3 ), we did not observe respiratory tracheae of eggs nor shrunken fruit in our study that would be indicative of high rates of oviposition.

In addition to having "apparent" repellent effects in the field, Octabor had a negative effect on SWD mortality, but the temporal pattern of mortality was not as we hypothesized. We thought that similar to the repellent effect, mortality of flies would be highest at day 0 and then decline rapidly with time. However, Figure 3 shows the opposite phenomenon. This is difficult to explain, but we put forth the following hypothesis. An explanation might be the chemical transformation that Octabor experiences under field conditions over time. We hypothesize that in the field on fruit over time Octabor, or disodium octaborate tetrahydrate, tends to chelate with certain organic compounds (Lloyd, 1998), possibly reducing its toxicity to flies, but potentially still being repellent. However, especially in an aqueous sugar environment (dew on fruit and leaves) many of the oxygen borate compounds transform to the more acidic boric acid form (Lloyd, 1998). If this is the case, then we might have observed repellency to ovipositing flies from disodium octaborate tetrahydrate and subsequent delayed mortality to flies from increased concentrations of boric acid.

\section{Conclusion}

Further study is needed to test whether this temporal dynamic in repellency and mortality can be understood to allow optimization of Octabor's potential as an insecticide. Increased sugar concentrations and decreased Octabor concentrations may reduce Octabor's "apparent" repellent effects and attract more spotted wing drosophila flies to ingest the mixture. Past experiments have tested the effect of boron-rich diets on Drosophila melanogaster mortality and fecundity and found that both mortality and reduced fecundity result (Erdem et al., 2016). Reduction in fecundity as a result of ingesting sodium borates appears to occur across insect families and orders. This phenomenon has been recorded in mosquitos (Bhami and Das, 2015), cockroaches (Habes et al., 2013), and moths (Hyršl et al., 2007). Replicating the experiments conducted by Erdem et al., (2016) and those presented here using D. Suzukii may further our understanding of Octabor's effect on spotted wing drosophila and its management. The short generational period of the spotted wing drosophila make fecundity an important target in control. A similar strategic approach by Alnajjar et al. (2018), focusing on fecundity of the spotted wing drosophila with pathogenic fungi, found that sub-lethal doses of the fungus, Beauveria bassiana (Bals.) Vuill. reduced fecundity of infected spotted wing drosophila female flies. The delayed toxic effect of Octabor on spotted wing drosophila could be offset by a strong effect on fecundity that would dampen future generations within the fruit growing season. Until further experimentation has been conducted, Octabor should not be recommended as an insecticide in an agricultural setting, but it does appear to have characteristics that warrant further study. 


\section{Acknowledgement}

We would like to thank Ms. E. Ballman for her help in acquiring supplies and maintaining the spotted wing drosophila cultures in the laboratory. The semi-field study was carried out at the University of Maine Blueberry Hill Farm. This is the Maine Agricultural and Forestry Experiment Station journal article number 3562. Funding for this project was provided by the National Institute of Food and Agriculture, U.S. Department of Agriculture Specialty Crops Research Initiative under Agreement No. 2015-51181-24252, and the University of Maine Agricultural and Forestry Research Station Hatch Project ME021505.

\section{References}

Alnajjar, G., Collins, J. \& Drummond, F.A. (2017). Behavioral and preventative management of Drosophila suzukii Matsumura (Diptera: Drosophilidae) in Maine wild blueberry (Vaccinium angustifolium Aiton) through attract and kill trapping and insect exclusion-netting. International Journal of Entomology and Nematology, 3(1), 51-61.

Alnajjar, G., Drummond, F.A. \& Groden, E. (2018). Laboratory and field susceptibility of Drosophila suzukii Matsumura (Diptera: Drosophilidae) to entomopathogenic fungal mycoses. Journal of Agricultural and Urban Entomology, 33(1): 111-132.

Anonymous. (2017). The Household Products Database of the National Library of Medicine. https://tehip@teh.nlm.nih.gov (20 September, 2017)

Asplen, M.K., Anfora, G., Biondi, A., Choi, D.S., Chu, D., Daane, K.M. \& Desneux, N. (2015). Invasion biology of spotted wing drosophila (Drosophila suzukii): a global perspective and future priorities. Journal of Pest Sciences, 88(3), 469-494.

Ballman, E.S., Collins, J.A. \& Drummond, F.A. (2017). Predation on Drosophila suzukii (Diptera: Drosophilidae) pupae in Maine wild blueberry fields. Journal of Economic Entomology, 110(6), 2308-2317.

Ballman, E.S. \& Drummond, F.A. (2018). Infestation of wild fruit by Drosophila suzukii surrounding Maine wild blueberry fields. Journal of Agricultural and Urban Entomology, $33(1), 61-70$.

Bhami, L.C. \& Das, S.S.M. (2015). Boric acid ovicidal trap for the management of Aedes species. Journal of Vector BorneDdiseases, 52(2), 147.

Bohinc, T. \& Trdan, S. (2014). Control of spotted wing drosophila (Drosophila suzukii [Matsumura], Diptera, Drosophilidae) with the emphasis on environmentally acceptable methods. Acta Agriculturae Slovenica, 103, 323-329.

Calvert, G.M., Karnik, J., Mehler, L., Beckman, J., Morrissey, B., Sievert, J., Barrett, R., Lackovic, M., Mabee, L., Schwartz, A. \& Mitchell, Y. (2008). Acute pesticide poisoning among agricultural workers in the United States, 1998-2005. American Journal of Industrial Medicine, 51(12), 883-898.

Çevik, M. and Erden, A. (2012). The course of habituation of the proboscis extension reflex 
can be predicted by sucrose responsiveness in Drosophila. Plos One 7:e39863.

Collins, J.A. and Drummond, F.A. (2014). Spotted wing drosophila control in the laboratory, 2013. Arthropod Management Tests, 39 (Electronic Journal), L1.

Collins, J.A. and Drummond, F.A. (2016). Spotted wing drosophila control, 2014. Arthropod Management Tests 201640 (1), C2doi: 10.1093/amt/tsv012

Cormier D., Veilleux J. \& Firlej A. (2015). Exclusion net to control spotted wing drosophila in blueberry fields. International Organization for Biological and Integrated Control-West Palearctic Regional Section Bulletin, 109, 181-184.

Dayer, M.S. \& Karvandian, K. (2016). Toxicity of Metarhizium anisopliae (Deuteromycota: Hyphomycetes) and boric acid against nosocomial cockroaches, Blattella germanica. Arthropods, 5(3), 114-124.

Drummond, F.A., Ballman, E., Collins, J., \& Yarborough, D.E. (2017). Insects - 210-Spotted Wing Drosophila: Pest Biology and IPM Recommendations for Wild Blueberries. University of Maine Cooperative Extension fact Sheet no. 210,

https://extension.umaine.edu/blueberries/factsheets/insects/210-spotted-wing-drosophila/ (24 January, 2018)

Erdem, M., Büyükgüzel, E. \& Büyükgüzel, K. (2016). Effect of dietary sodium tetraborate on adult longevity and fecundity of Drosophila melanogaster (Diptera: Drosophilidae). Journal of Entomological Science, 51(4), 305-313.

Fanning, P.D., Grieshop, M.J. \& Isaacs, R. (2018). Efficacy of biopesticides on spotted wing drosophila, Drosophila suzukii Matsumura in fall red raspberries. Journal of Applied Entomology, 142(1-2), 26-32.

Habes, D., Morakchi, S. Aribi, N.,Farine, J.P., \& Soltani, N. (2006). Boric acid toxicity to the German cockroach, Blattella germanica: Alterations in midgut structure, and acetylcholineestrease and glutathione S-transferase activity. Pesticide Biochemistry and Physiology, 84, $17-24$.

Habes, D., Messiad, R., Gouasmia, S. and Grib, L., 2013. Effects of an inorganic insecticide (boric acid) against Blattella germanica: Morphometric measurements and biochemical composition of ovaries. African Journal of Biotechnology, 12(18), 2492-2497..

Hagen, K.S. \& Hale, R. (1974). Increasing natural enemies through use of supplementary feeding and non-target prey. In Proceedings of the Summer Institute on Biological Control of Plant Insects and Diseases. University Press of Mississippi, Jackson.

Hamby, K.A. \& Becher, P.G. (2016). Current knowledge of interactions between Drosophila suzukii and microbes, and their potential utility for pest management. Journal of Pest Science, 89(3), 621-630.

Hardin, J.W. \& Hilbe, J.M. (2003). Generalized Estimating Equations. Chapman and Hall/CRC, Boca Raton, FL, 222pp. 
Hampton E., Koski C., Barsoian O., Faubert H., Cowles R.S., and Alm S.R. (2014). Use of early ripening cultivars to avoid infestation and mass trapping to manage Drosophila suzukii (Diptera: Drosophilidae) in Vaccinium corymbosum (Ericales: Ericaceae). Journal of Economic Entomology, 107, 1849 - 1857.

Horton, M.K., Jacobson, J.B., McKelvey, W., Holmes, D., Fincher, B., Quantano, A., Diaz, B.P., Shabbazz, F., Shepard, P., Rundle, A. \& Whyatt, R.M. (2011). Characterization of residential pest control products used in inner city communities in New York City. Journal of Exposure Science and Environmental Epidemiology, 21(3), 291-301.

Hyršl, P., Büyükgüzel, E. \& Büyükgüzel, K. (2007). The effects of boric acid-induced oxidative stress on antioxidant enzymes and survivorship in Galleria mellonella. Archives of Insect Biochemistry and Physiology, 66(1), 23-31.

JMP. (2015). Version 12. SAS Institute Inc., Cary, NC, 1989-2007.

Klotz, J.H. \& Moss, J.I. (1996). Oral toxicity of a boric acid-sucrose water bait to Florida carpenter ants (Hymenoptera: Formicidae). Journal of Entomological Science, 31(1), 9-12.

Klotz, J.H., Vail, K.M. \& Willams, D.F., (1997). Toxicity of a boric acid-sucrose water bait to Solenopsis invicta (Hymenoptera: Formicidae). Journal of Economic Entomology, 90(2), 488-491.

Klotz, J.H., Greenberg, L., Amrhein, C. \& Rust, M.K. (2000). Toxicity and repellency of borate-sucrose water baits to Argentine ants (Hymenoptera: Formicidae). Journal of Economic Entomology, 93(4), 1256-1258.

Knight, A.L., Basoalto, E., Yee, W., Hilton, R. \& Kurtzman, C.P. (2016). Adding yeasts with sugar to increase the number of effective insecticide classes to manage Drosophila suzukii (Matsumura)(Diptera: Drosophilidae) in cherry. Pest Management Science, 72(8), 1482-1490.

Lloyd, J.D. (1998). Borates and their biological applications. International Research Group on Wood Protection, 98, 1-67.

Loeb, G., Heidenreich, C., McDermott, L., Jentsch, P., Breth, D. \& Carroll, J. (2013). Chemical control of spotted wing drosophila in berry crops. NY Berry News, 12, 1-2.

Rice, K.B., Short, B.D. \& Leskey, T.C. (2017). Development of an attract-and-kill strategy for Drosophila suzukii (Diptera: Drosophilidae): evaluation of attracticidal spheres under laboratory and field conditions. Journal of Economic Entomology, 110(2), 535-542.

Summy, K.R. \& Little, C.R. (2008). Using color infrared imagery to detect sooty mold and fungal pathogens of glasshouse-propagated plants. HortScience, 43(5), 1485-1491.

Sudd, J.H. \& Sudd, M.E. (1985). Seasonal changes in the response of wood-ants (Formica lugubris) to sucrose baits. Ecological Entomology, 10(1), 89-97.

Van Duin, M., Peters, J.A., Kieboom, A.P.G. \& Van Bekkum, H. (1984). Studies on borate 


\section{Macrothink}

Journal of Agricultural Studies

ISSN 2166-0379 2018, Vol. 6, No. 3

esters 1: the $\mathrm{pH}$ dependence of the stability of esters of boric acid and borate in aqueous medium as studied by 11B NMR. Tetrahedron, 40(15), 2901-2911.

Wu, V.C.H., Drummond, F.A., Tadepalli, S., Camire, M.E., Davis-Dentici, K., Bushway, A. \& Yarborough, D.E. (2017). Salmonella spp. dynamics in wild blueberry, Vaccinium angustifolium Aiton. World Microbiology, 4(1), 64-71.

Yarborough, D., Drummond, F.A. \& Collins, J.A. (2018). Insect control guide for wild blueberries. University of Maine Cooperative Extension Fact Sheet No. 209, UMaine Extension No. 2001, 14 pp (28 May, 2018).

\section{Copyright Disclaimer}

Copyright for this article is retained by the author(s), with first publication rights granted to the journal.

This is an open-access article distributed under the terms and conditions of the Creative Commons Attribution license (http://creativecommons.org/licenses/by/4.0/). 